\title{
Abdominoscrotal hydrocele with bilateral hydronephrosis in an adult: Case report
}

\author{
Bircan Mutlu, Yusuf Ozlem Ilbey, Alper Bitkin, Ali İhsan Taşçı \\ Bakırköy Dr. Sadi Konuk Training and Research Hospital, Istanbul, Turkey.
}

\begin{abstract}
「Summary
Abdominoscrotal hydrocele is a rare entity with unclear etiology which may be diagnosed with general examination and ultrasound imaging. During examination it may misinterpreted as acute urinary retention of the bladder (globe-like) especially if associated with hydronephrosis. It should be treated surgically. Here we present a case of left abdominoscrotal hydrocele with accompanying left grade 2 and right grade 1 hydronephrosis.
\end{abstract}

KEY WORDS: Hydrocele; Hydronephrosis; Ultrasound.

Submitted 10 January 2013; Accepted 28 February 2013

No conflict of interest declared

\section{INTRODUCTION}

Abdominoscrotal hydrocele (ASH) is a rare entity with unclear etiology. It extends into the abdominal cavity through the inguinal canal $(1,2)$. Mostly observed in pediatric patients, ASH is scarcely described in adult population with only a few cases associated with one sided hydronephrosis reported in the literature $(3,4)$. We present a case of ASH with bilateral hydronephrosis.

\section{Case presentation}

A 49-year-old male was admitted to our clinic with progressively increasing left scrotal swelling along a period of one year. During initial physical examination lower abdominal mass on the left and hydrocele of the left testis were observed (Figure 1). Hydrocele had simultaneous fluctuation with the lower abdominal swelling. In spite of clinical diagnosis based on physical findings and ultrasound imaging an urethral Foley catheter was inserted to rule out the presence of urinary retention and associated hydronephrosis demonstrating an empty bladder. Bilateral hydronephrosis occurred as a result of the compression of the bladder and the left ureter by the sac (Figure 2, 3). Surgery was scheduled by inguinal approach in order to perform an high ligation of the processus vaginalis with complete excision of the abdominal component of the lesion. During the abdominal dissection of the sac we injured the peritoneum and it was repaired. We also mobilised the scrotal part of the sac in order to excise the

Figure 1.

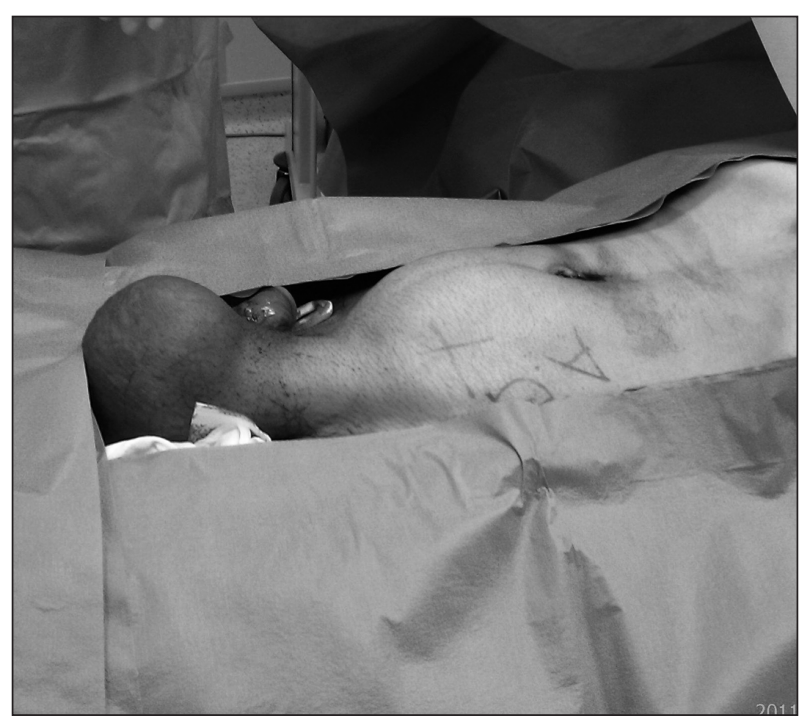


Figure 2.

A: Computed tomography images demonstrating right grade one and left grade two hydronephrosis. B: Abdominal part of abdominoscrotal hydrocele.

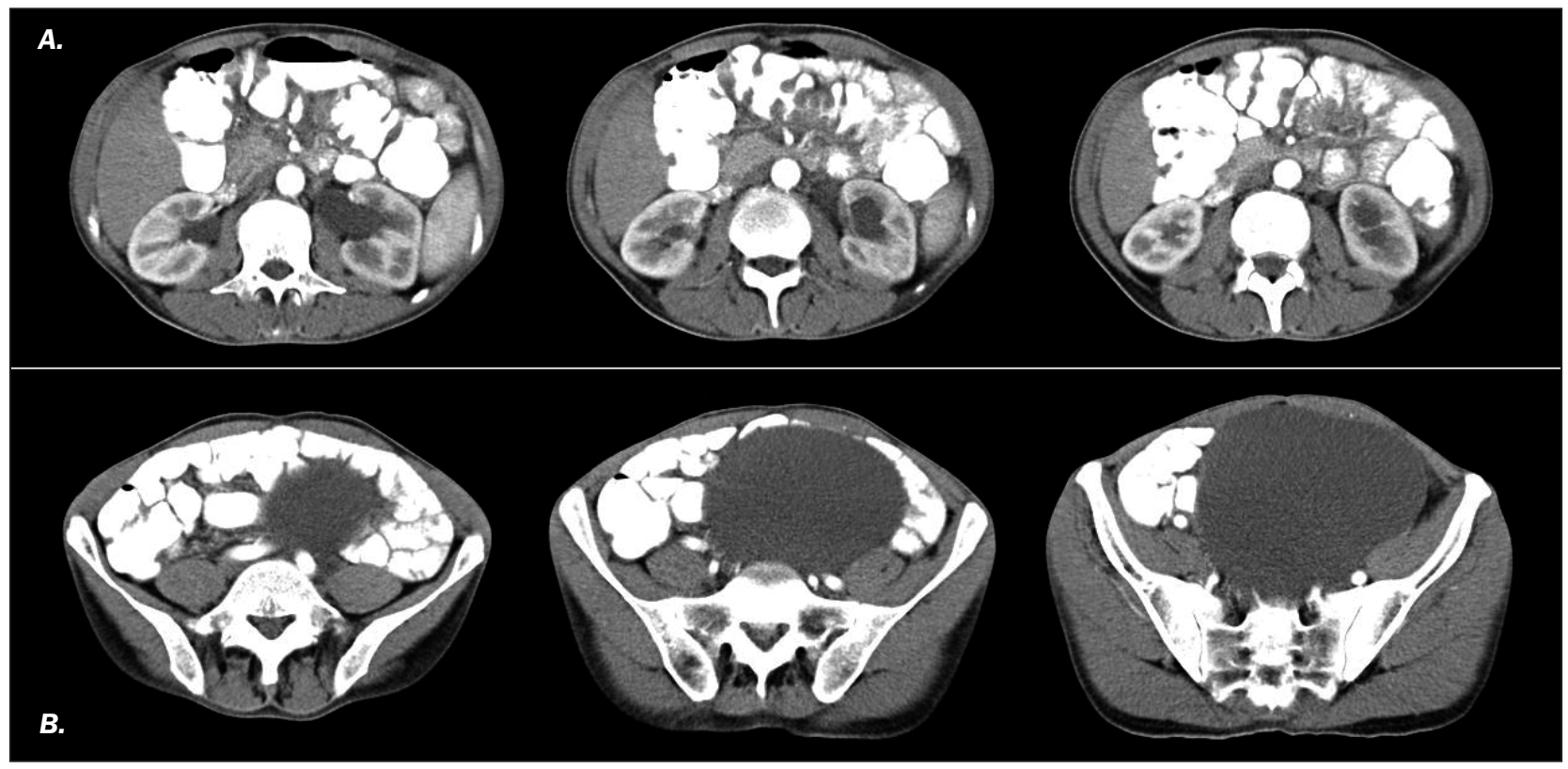

Figure 3.

A: Compression of abdominoscrotal hydrocele on left side of the bladder. B: bladder - $\mathrm{H}$ : hydrocele. B: Inguinal and scrotal part of abdominoscrotal hydrocele. B: bladder - H: hydrocele - T: testicle.

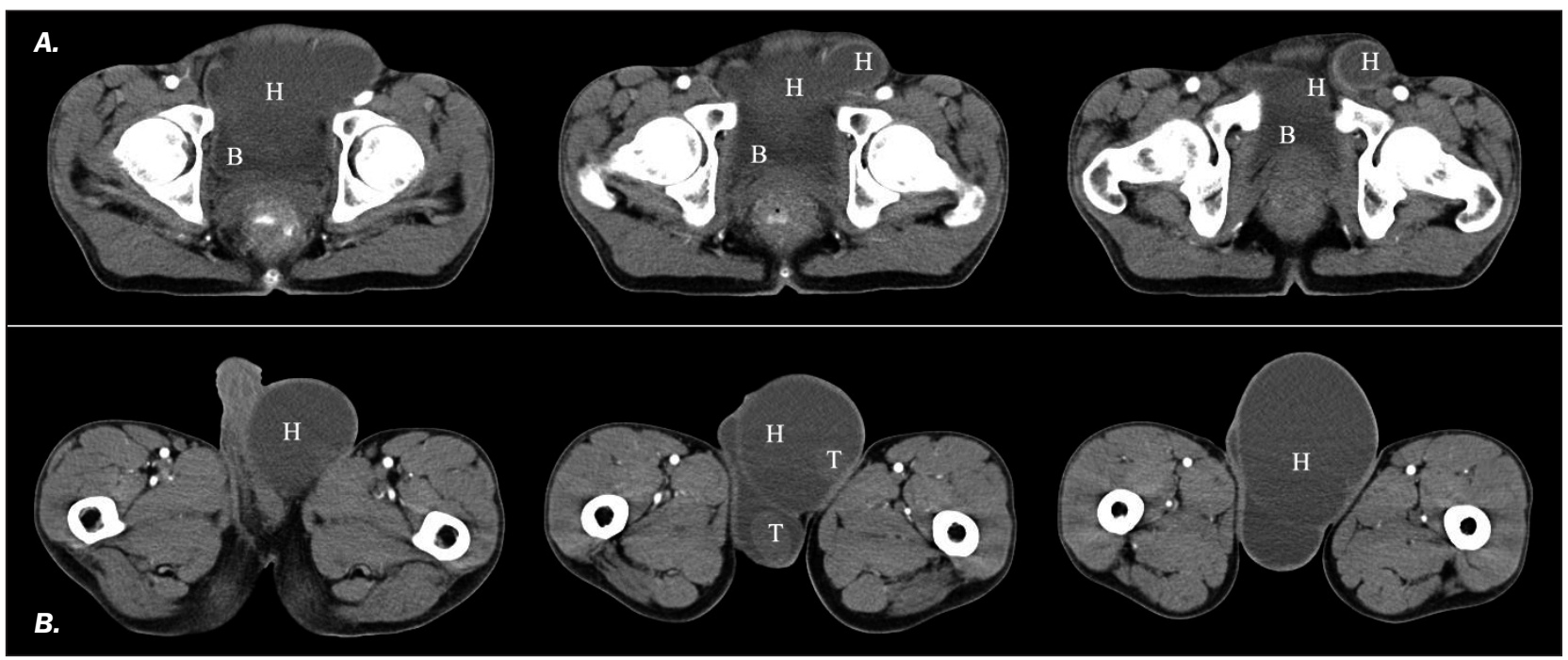

tunica vaginalis of the testis and suture the edges of the remaining tunica vaginalis posterior to the testis. Mesh (Lichtenstein) method was used for inguinal hernia repair. Testis and cord were normal. The postoperative period was uneventful.

\section{Discussion}

The etiology of ASH is not clear but there is general consensus on the need of surgical treatment. According to a Pubmed search there is only one case which Authors successfully managed by conservative approach (5). ASH is not a real benign condition, because it may be complicated with acute appendicitis, and it may lead to ureterohydronephrosis, testicular dismorphism and even leg edema in pediatric patients $(6,7)$. In our case at initial diagnosis we have observed bilateral hydronephrosis. ASH should be considered for the differential diagnosis of bilateral hydronephrosis. Mostly, it is one sided but in the literature bilateral ASH is also reported (8). Paratesticular malignant mesothelioma associated with ASH has also been reported in a 14-year-old boy (9). Ultrasound, magnetic resonance imaging (MRI) and computed tomography (CT) may be used for the diagnosis. During surgical treatment of ASH, dilated inguinal ring due to large sac shoud be repaired and mesh method should be used to avoid secondary herniation. Although open surgery is generally a preferred option, as we did, Bouhadiba et al. reported laparoscopic excision of ASH (10) 


\section{References}

1. Celayir AC, Akyüz U, Ciftlik H, et al. A critical observation about the pathogenesis of abdominoscrotal hydrocele. J Pediatr Surg. 2001; 36:1082-4.

2. Kaplan M, Atakan IH, Aktoz T, Inci O. Giant unilateral abdominoscrotal hydrocele in an adult: case report.Int Urol Nephrol. 2006; 38:667-70.

3. Avolio L, Chiari G, Caputo MA, Bragheri R. Abdominoscrotal hydrocele in childhood: is it really a rare entity? Urology. 2000; 56:1047-9.

4, Singh D, Aga P, Goel A. Giant unilateral hydrocele "en-bisac" with right hydronephrosis in an adult: A rare entity. Indian J Urol. 2011; 27:142-3.

5. Upadhyay V, Abubacker M, Teele R. Abdominoscrotal hydrocele-is there a place for conservative management? Eur J Pediatr Surg. 2006; 16:282-4.
6. Halilbasic A, Hotic N, Skokic F, et al. Both-sided large abdominoscrotal hydrocele associated with testicles atrophy. Med Arh. 2011; 65:182-4.

7. Faure A, Bouali O, Chaumoitre K, et al. Abdominoscrotal hydrocele with leg edema in a 4-month-old boy. Prog Urol. 2009; 19:639-42.

8. Arslan AS, Incesu L, Yalin T, et al. Bilateral abdominoscrotal hydrocele. Abdom Imaging. 1996; 21:177-178.

9. Velasco AL, Ophoven J, Priest JR, Brennom WS. Paratesticular malignant mesothelioma associated with abdominoscrotal hydrocele. J Pediatr Surg. 1988; 23:1065-7.

10. Bouhadiba N, Godbole P, Marven S. Laparoscopic excision of abdominoscrotal hydrocele. J Laparoendosc Adv Surg Tech A. 2007; 17:701-3.

\section{Correspondence}

Bircan Mutlu, MD (Corresponding Author)

Tevfik Saglam Cad. No:11 Zuhuratbaba, Istanbul, Turkey mutlubircan@yahoo.com

Yusuf Ozlem Ilbey, MD

ozlemyusufilbey@hotmail.com

Alper Bitkin, MD

alperbitkin@gmail.com

Ali İhsan Taş̧ı, MD

aliihsantasci@hotmail.com

Bakırköy Dr.Sadi Konuk Training and Research Hospital, Istanbul, Turkey 